\title{
In Vitro Apoptosis Induction by Fenofibrate in Lymphoma and Multiple Myeloma
}

\author{
LEONARD CHRISTOPHER SCHMEEL ${ }^{1,2}$, FREDERIC CARSTEN SCHMEEL ${ }^{1,2}$ and INGO G.H. SCHMIDT-WOLF ${ }^{2}$ \\ ${ }^{1}$ Department of Radiology and Radiation Oncology, University Hospital Bonn, Bonn, Germany; \\ ${ }^{2}$ Center for Integrated Oncology (CIO), Medical Clinic and Policlinic III, \\ University Hospital Bonn, Bonn, Germany
}

\begin{abstract}
Background/Aim: Recent innovations in the treatment of multiple myeloma have enriched our therapeutic repertoire regarding the treatment of multiple myeloma during the last decades. However, despite today's therapies many multiple myeloma (MM) patients experience relapse of disease and eventually remain incurable. Wnt/ $\beta$-catenin signaling has been demonstrated in lymphoma and $M M$, rendering related signaling molecules promising therapeutic targets. Fenofibrate, an extensively scrutinized and widely used drug for primary hypercholesterolemia or mixed dyslipidemia, has proven anticarcinogenic properties mediated by peroxisome proliferator-activated receptor-alpha (PPAR $\alpha)$ agonism, thereby also influencing WNT-associated signaling molecules. Materials and Methods: The antitumor apoptotic effect of fenofibrate at doses ranging from 0.1-200 $\mu \mathrm{M}$ was investigated on a total of seven human, two murine myeloma/lymphoma cell lines and two healthy control cell lines, as determined by 3'3Dihexyloxacarbocyanine iodide (DiOC6) and propidium iodide (PI) staining in flow cytometry. Results: Fenofibrate significantly reduced viability due to apoptosis induction in all investigated myeloma and lymphoma cell lines in a dosedependent manner, whereas healthy control cells were less sensitive. Conclusion: Our results provide a rationale for future in vitro and in vivo studies with fenofibrate as a safe and welltolerated agent in MM and lymphoma treatment.
\end{abstract}

Multiple myeloma (MM) is a hematological malignancy induced by monoclonal malignant secretory plasma cells in the bone marrow and is usually associated with monoclonal

Correspondence to: Prof. Dr. med. Ingo G.H. Schmidt-Wolf, University Hospital Bonn, Center for Integrated Oncology (CIO), Sigmund-Freud-Straße 25, 53105 Bonn, Germany, Tel: +49 22828717050, Fax: +49 2282879080059, e-mail: Ingo.SchmidtWolf@ukbonn.de

Key Words: Fenofibrate, apoptosis, multiple myeloma, lymphoma, therapy, Wnt signaling. protein in peripheral blood and/or urine $(1,2)$. Innovative therapy strategies including immunomodulatory drugs (IMiDs) like bortezomib, lenalidomide and thalidomide as well as advanced cell-based treatment approaches improved treatment outcome and patient survival $(3,4)$. Supportive therapies like localised radiotherapy can additionally improve patients' quality of life in advanced disease stages (5).

Wnt signaling, in general restricted solely to the embryonic development, represents a tumor-specific signaling cascade causing and perpetuating carcinogenic effects in both the oncogenesis as well as the propagation of lymphoma and MM (6-15). A targeted inhibition of the Wnt pathway, therefore, impedes tumor progression, and thus renders Wnt signaling molecules a promising therapeutic target for MM $(15,16)$.

In recent studies, we confirmed the efficacy of multiple agents, inter alia clofibrate as an analogue of fenofibrate, by targeting Wnt/beta-catenin signaling molecules, particularly in hematopoietic malignancies (17-32). Fenofibrate is chemically related to other known Wnt inhibitors and has already proven anticarcinogenic properties in numerous neoplasms (33). Herein we demonstrated, for the first time, that fenofibrate is efficacious in the in vitro treatment of MM through inducing significant apoptosis.

\section{Materials and Methods}

Cell lines and culture conditions. Cell lines were obtained from DSMZ (Braunschweig, Germany) or ATCC (LGC Standards, Wesel, Germany) and incubated at $37^{\circ} \mathrm{C}$ with $5 \% \mathrm{CO}_{2}$ at $90 \%$ humidity. The human myeloma cell lines KMS 18, OPM-2, RPMI8226 and U-266 (all obtained from DMSZ) were cultured in RPMI1640-medium (PAA, Pasching, Austria), supplemented with 5\% heat-inactivated fetal calf serum FCS (Invitrogen, Darmstadt, Germany) and $1 \%$ penicillin-streptomycin (Seromed, Jülich, Germany). Human lymphoma cell lines Raji, SU-DHL-4 and Oci Ly 8 Lam 53 cells were cultured under identical conditions as human myeloma cell lines. MPC-11 is a murine plasmocytoma cell line and RAW 264,7 is a leukaemia monocyte macrophage cell line. Cells were cultured in RPMI-1640 medium supplemented with 
$5 \%$ heat-inactivated FCS and $1 \%$ penicillin/streptomycin. RAW 264,7 cells were harvested using $0.05 \%$ trypsin-EDTA solution (Invitrogen).

The human colon fibroblast cell line CCD-18Co was obtained from ATCC and cultured in ATCC-formulated Eagle's Minimum Essential Medium (LGC Standards) supplemented with $15 \%$ of heat-inactivated FCS and $1 \%$ penicillin-streptomycin. Cells were harvested by $0.05 \%$ trypsin-EDTA solution (Invitrogen), centrifuged at $1,200 \times g$ for $7 \mathrm{~min}$ and re-suspended in $1 \mathrm{~mL}$ media to define the cell count. Media were renewed at least every 3 days.

Human samples. Peripheral blood lymphocytes (PBLs) were isolated from blood samples of healthy volunteers using Ficoll density gradient centrifugation (Lymphoprep; Nycomed, Oslo, Norway). Blood from buffy coats was diluted 1:2 with phosphate-buffered saline (PBS)/1\% bovine serum albumin (BSA) (both from PAA) and used for a Ficoll gradient (Lymphoprep). The leukocyte layer was transferred to new tubes after centrifugation at $800 \times g$ for 30 minutes. Cells were washed three times with PBS/1\%BSA and resuspended in RPMI-1640 medium supplemented with $10 \%$ FCS, $1 \%$ penicillin/streptomycin and $2.5 \%$ HEPES buffer solution (PAA).

Drugs and chemical reagents. Fenofibrate was purchased from Sigma-Aldrich (Steinheim, Germany) and tested at concentrations ranging from $0.1-200 \mu \mathrm{M}$ for $72 \mathrm{~h}$.

3'3-Dihexyloxacarbocyanine iodide (DiOC6) and propidium iodide (PI) staining. Reduced mitochondrial transmembrane potential is known to occur late in the apoptotic process. We used DiOC6 staining and flow cytometry to assess the mitochondrial transmembrane potential. Therefore, $1 \times 10^{5}$ cells were plated in $3 \mathrm{ml}$ medium in 6-well plates. Fenofibrate was dissolved in dimethyl sulfoxide (DMSO) (Invitrogen) and added to the medium at different concentrations for three days. Staining with DiOC6 for detecting viable cells and with PI, which binds to DNA in necrotic cells, was used for the apoptosis assay, measured by a fluorescenceactivated cell sorter (FACS; BD FACSCanto II, Becton Dickinson Biosciences, Franklin Lakes, NJ, USA). The medium containing drug-treated cells was transferred from each well into a glass tube. Then cells were centrifuged at $800 \times g$ for $7 \mathrm{~min}$, washed with phosphate buffered saline (PBS, pH 7.4) (Roti-Stock 10x; CarlRoth, Karlsruhe, Germany) and stained after repeated centrifugation by adding $500 \mu \mathrm{l}$ staining solution (RPMI-1640, $0.5 \%$ bovine serum albumin [BSA], $80 \mathrm{nM}$ DiOC6) for $15 \mathrm{~min}$ at $37^{\circ} \mathrm{C}$. After another washing step with PBS/1\% BSA, cells were re-suspended in $500 \mu \mathrm{l}$ $\mathrm{PBS} / 1 \%$ BSA. FACS analysis was performed immediately after the addition of $5 \mu \mathrm{l}$ PI solution $(100 \mu \mathrm{g} / \mathrm{ml})$ with a FACS (BD FACSCanto II, Becton Dickinson Biosciences, Franklin Lakes, NJ, USA). Approximately 10,000 counts were made for each sample. In this assay, viable cells show high fluorescence intensity for DiOC6 and a low fluorescence for PI. Necrotic cells fluoresce in an opposite manner, with high intensity for PI and a low intensity for DiOC6. Early apoptotic cells show low fluorescence for both DiOC6 and PI. Cells with high fluorescence intensity for both DiOC6 and PI correspond either to late apoptotic cells as apoptotic bodies or debris.

Cell viability assay with 3-(4,5-dimethylthiazol-2-yl)-2,5-diphenyltetrazolium-bromide (MTT). The efficacy of fenofibrate in CCD-18Co cells was determined by cell viability in the MTT assay. Viable cells convert
Table I. Inhibitory concentration $\left(I C_{50}\right)$ of fenofibrate for human lymphoma, human and murine multiple myeloma, murine leukemia and control cell lines. CCD-18Co cells and peripheral blood lymphocytes $(P B L)$ served as controls. A total of $1 \times 10^{5}$ cells were cultured with different concentrations of fenofibrate for $72 \mathrm{~h}$. Cell viability and apoptosis was measured by 3'3-Dihexyloxacarbocyanine iodide (DiOC6) and propidium iodide (PI) staining in flow cytometry. CCD18Co cells were investigated by the 3-(4,5-dimethylthiazol-2-yl)-2,5diphenyltetrazolium-bromide (MTT) assay. Results represent the mean of data from at least three independent experiments each.

\begin{tabular}{lc}
\hline & $\mathrm{IC}_{50}(\mu \mathrm{M})$ \\
\cline { 2 - 2 } Cell line & Fenofibrate \\
\hline KMS 18 & $125 \mu \mathrm{M}$ \\
OPM-2 & $37 \mu \mathrm{M}$ \\
RPMI-8226 & $36 \mu \mathrm{M}$ \\
U-266 & $26 \mu \mathrm{M}$ \\
MPC-11 & $42 \mu \mathrm{M}$ \\
Raji & $33 \mu \mathrm{M}$ \\
RAW 264,7 & $93 \mu \mathrm{M}$ \\
Oci Ly 8 Lam 53 & $30 \mu \mathrm{M}$ \\
SU DHL 4 & $42 \mu \mathrm{M}$ \\
CCD-18Co & $>400 \mu \mathrm{M}$ \\
PBL & $97 \mu \mathrm{M}$ \\
\hline
\end{tabular}

the yellow MTT (Sigma Aldrich, Steinheim, Germany) into purple formazan when taken-up into mitochondria. Previously, cells were plated at $1 \times 10^{4}$ well/ $100 \mu \mathrm{l}$ in 96 -well plates, left to adhere overnight in the incubator. $24 \mathrm{~h}$ later media were removed and renewed containing various concentrations of fenofibrate. After $69 \mathrm{~h} 1 \mu \mathrm{L}$ MTT $(5 \mathrm{mg} / \mathrm{ml})$ was added to each well and incubated for another $3 \mathrm{~h}$. Then $80 \mu \mathrm{L}$ of the media were removed and $50 \mu \mathrm{l}$ of acidified isopropanol was added for cell lysis. After shaking for $10 \mathrm{~min}$ the amount of formazan was measured at $565 \mathrm{nM}$. The measured amount of formazan in treated cells was compared to untreated cells.

Statistical analysis. Values are given as mean \pm standard deviation (SD). At least three separate and independent experiments were performed with each cell line. Paired, two-tailed Student's $t$-test was used for statistical analysis. A $p$-value less than 0.05 was considered significant.

\section{Results}

Titration of fenofibrate. The mean $50 \%$ inhibitory concentration $\left(\mathrm{IC}_{50}\right)$ after $72 \mathrm{~h}$ was calculated following titration. Fenofibrate concentrations inducing a significant decrease in viability were, therefore, determined. PBLs and CCD-18Co colonic fibroblasts served as healthy controls. All except CCD-18Co cells were investigated by DiOC6 and PI staining in flow cytometry. CCD-18Co cells were investigated by MTT. IC $_{50}$ values of fenofibrate employed after $72 \mathrm{~h}$ of incubation are given in Table I. 


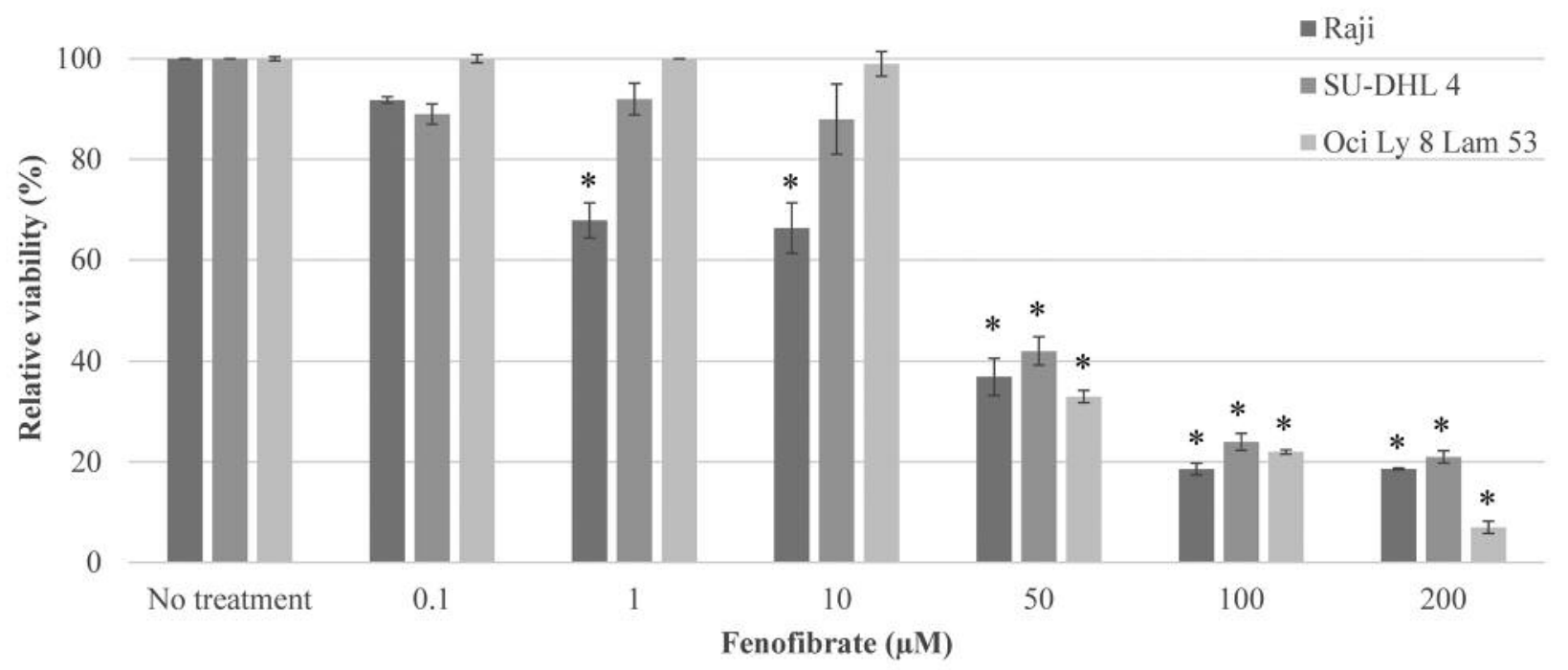

Figure 1. Effect of fenofibrate on viability of Raji, SU DHL 4 and Oci Ly 8 Lam 53 human lymphoma cells. Cells were cultured with fenofibrate for $72 \mathrm{~h}$. Cell viability and apoptosis was measured by 3'3-Dihexyloxacarbocyanine iodide (DiOC6) and propidium iodide (PI) staining in flow cytometry. Results represent data from three separate experiments. Data are shown as mean $\pm S D .{ }^{*} p<0.05$ compared to untreated cells.

Effect of fenofibrate on viability of human lymphoma cells. Fenofibrate treatment with concentrations from $50 \mu \mathrm{M}$ and above significantly decreased lymphoma cell viability in all tested cell lines. The $\mathrm{IC}_{50}$ of Raji, SU-DHL-4 and Oci Ly 8 Lam 53 was attained after treatment with $33 \mu \mathrm{M}, 42 \mu \mathrm{M}$ and $30 \mu \mathrm{M}$, respectively. Figure 1 presents the respective results. Figure 2 (Panel A) presents exemplary flow cytometry results.

Effect of fenofibrate on viability of human myeloma cells. Comparably, the viability of the investigated myeloma cells decreased in a concentration-dependent manner after the addition of fenofibrate. In RPMI-8226 cell concentrations starting from $10 \mu \mathrm{M}$ were required for significant apoptosis induction. All remaining human myeloma cell lines except KMS-18 cells significantly underwent apoptosis following the treatment with $50 \mu \mathrm{M}$ of fenofibrate for $72 \mathrm{~h}$. KMS- 18 myeloma cells showed the lowest sensitivity towards fenofibrate treatment with an $\mathrm{IC}_{50}$ of $125 \mu \mathrm{M}$. Results were as shown in Figure 3. Figure 2 (Panel B and C) shows the corresponding flow cytometry results.

Effect of fenofibrate on viability of murine cells. The described induction of apoptosis for human myeloma and lymphoma cells was also reproducible in murine myeloma and leukaemia monocyte macrophage cells. Fenofibrate concentrations starting from $50 \mu \mathrm{M}$ were required for a significant decrease of viability in MPC-11 cells. However, RAW 264,7 cells were less sensitive towards fenofibrate with an $\mathrm{IC}_{50}$ of $93 \mu \mathrm{M}$. Results are given in Figure 4 .
Effect of fenofibrate on viability of healthy controls. CCD18Co colon fibroblasts and PBLs were chosen to investigate the toxic potential of fenofibrate towards healthy stroma cells and lymphocytes, respectively. CCD18-Co cells and PBLs tolerated far higher concentrations of fenofibrate compared to human and murine myeloma and lymphoma cell lines tested with an $\mathrm{IC}_{50}>400 \mu \mathrm{M}$ and $97 \mu \mathrm{M}$, respectively. Results are shown in Figure 5.

\section{Discussion}

MM represents a systemic hematologic malignancy due to degenerated plasma cells, caused by frequent gene mutations and/or chromosomal translocations (7). Today's therapy regimens consist of a primary initiated high-dose chemotherapy along with a facultative hematopoietic stem cell transplantation (34-37). However, most MM patients experience relapse of disease following chemotherapy $(3,35-41)$.

The development of MM cells relies on the bone marrow microenvironment. Herein, bone marrow stromal cells were shown to supply specific Wnt ligands facilitating and maintaining an inordinate propagation of MM cells (9, 3941). Targeting the Wnt signaling cascade promoting tumor differentiation and proliferation might, thus, represent a promising therapeutic approach in MM research and treatment, since its inhibition can prevent MM progression (11-15, 39).

In recent studies, we revealed various drugs as potent inducers of apoptosis in lymphoma and myeloma cells in vitro and partially proved in vivo efficacy in subsequent 
A

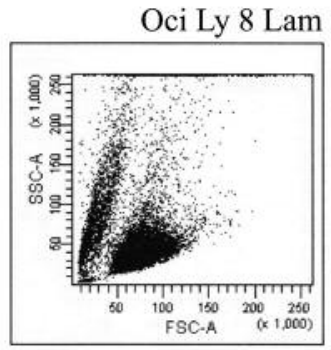

Oci Ly 8 Lam 53 + Fenofibrate
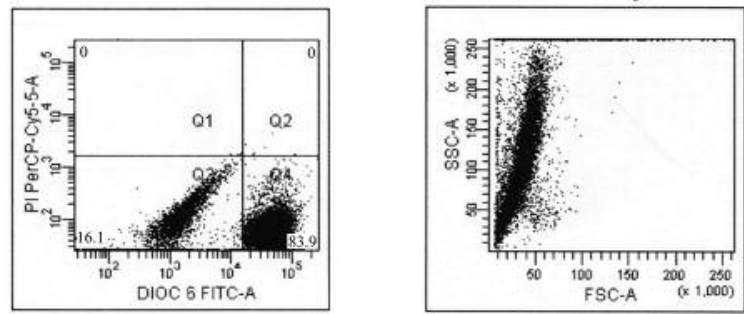

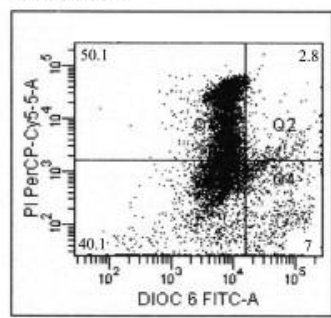

B

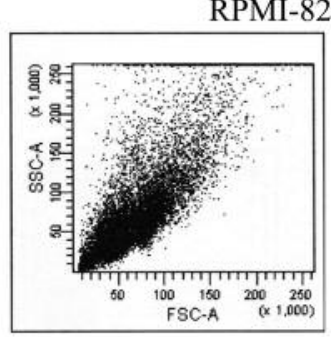

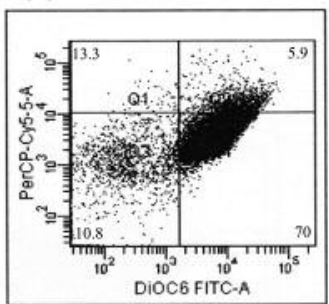

$\mathrm{C}$

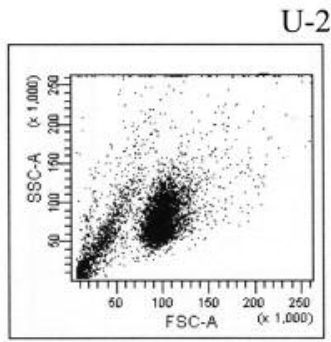

$\mathrm{U}-266+\mathrm{DMSO}$

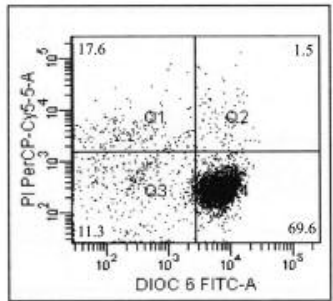

RPMI-8226 + Fenofibrate

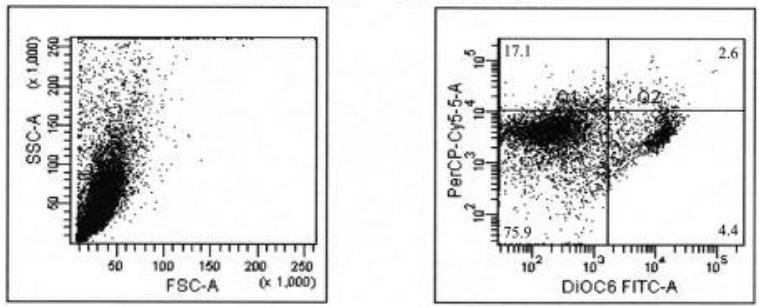

U-266 + Fenofibrate
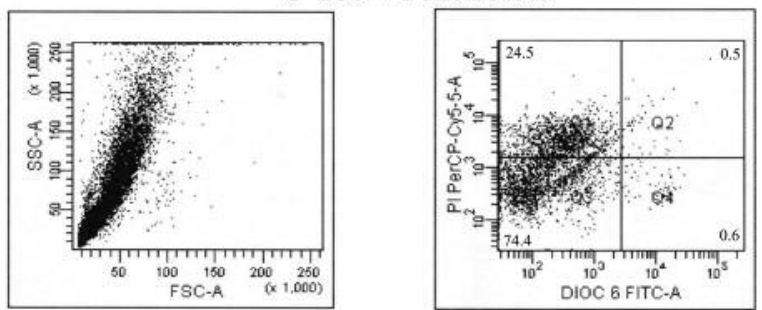

Figure 2. Exemplary results generated by flow cytometry. The relative number of cells is given within the quarters. (A) Oci Ly 8 Lam 53 cells before and after treatment with $200 \mu M$ fenofibrate. (B) RPMI-8226 cells before and after treatment with $200 \mu M$ fenofibrate. (C) U-266 cells before and after treatment with $100 \mu \mathrm{M}$ fenofibrate. Cells were treated with fenofibrate at different concentrations. Seventy-two hours after incubation, flow cytometry was performed.

animal studies. Several of these agents were demonstrated as efficacious in MM and lymphoma treatment due to an inhibition of the Wnt pathway as the underlying mechanism of action (17-32, 42, 43).

Fenofibrate is one of the most commonly prescribed fibrates since 1975. Like other fibrates it is used for the treatment of hypercholesterolemia and hypertriglyceridemia, predominantly in people at risk of cardiovascular disease. Lipid levels are lowered by interaction with the peroxisome proliferator-activated receptor alpha $(\operatorname{PPAR} \alpha) . \operatorname{PPAR} \alpha$, in return, induces lipoprotein lipase and reduces apoprotein CIII, leading to increased lipolysis and elimination of triglyceride-rich particles within the plasma. PPAR $\alpha$ represents a nuclear receptor of the steroid hormone receptor superfamily that has been shown to possess antiinflammatory properties and to exert various anticancer properties $(33,44,45)$. Multiple studies investigated a potential utilization in cancer therapy, particularly by ligands of PPAR $\alpha$, beyond their prescription as well-tolerated and extensively scrutinized lipid-lowering drugs (45).

Fenofibrate showed to exert direct antitumor and antiendothelial effects in vitro and significantly reduced melanoma, glioblastoma and fibrosarcoma cell growth in murine tumor models (33). In hepatocellular carcinoma cells, fenofibrate suppressed cell growth through a PPAR $\alpha$ independent mechanism by blocking Akt activation due to an increase of C-terminal modulator protein (CTMP) as the supposed mechanism of action (46). In glioblastoma cells treatment with $25 \mu \mathrm{M}$ fenofibrate effectively repressed cell growth by $\mathrm{G}$ (1) arrest, whereas cells treated with $50 \mu \mathrm{M}$ fenofibrate underwent a delayed and massive apoptosis after $72 \mathrm{~h}$ that was preceded by FoxO3A nuclear accumulation and expression of FoxO-dependent apoptotic protein (47). Interestingly, fenofibrate was also shown to inhibit the transcriptional activity of nuclear factor kappa-light-chainenhancer of activated B-cells (NF-kB) and to disrupt its 


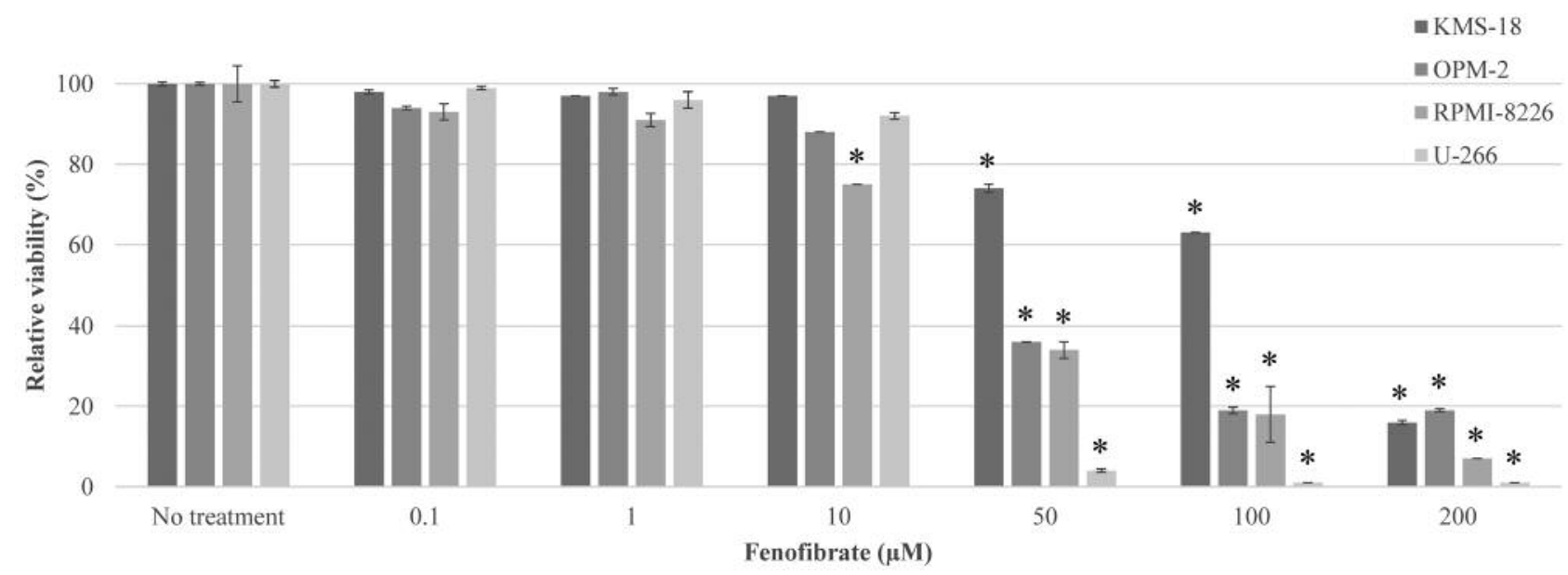

Figure 3. Effect of fenofibrate on viability of KMS-18, OPM-2, RPMI-8226 and U-266 human myeloma cells. Cells were cultured with fenofibrate for 72 h. Cell viability and apoptosis was measured by 3'3-Dihexyloxacarbocyanine iodide (DiOC6) and propidium iodide (PI) staining in flow cytometry. Results represent data from three independent experiments. Data are shown as the mean $\pm S D . * p<0.05$ compared to untreated cells.

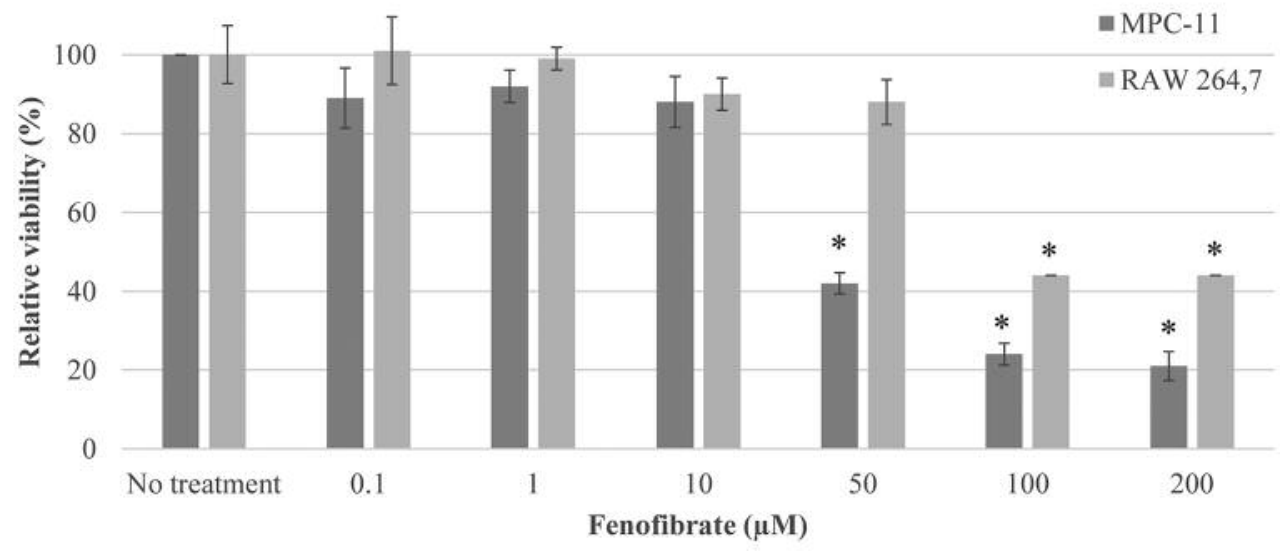

Figure 4. Effect of fenofibrate on viability of MPC-11 and RAW 264,7 murine myeloma and leukemia cells, respectively. Cells were cultured with fenofibrate for $72 \mathrm{~h}$. Cell viability and apoptosis was measured by 3'3-Dihexyloxacarbocyanine iodide (DiOC6) and propidium iodide (PI) staining in flow cytometry. Results represent data from at least three separate experiments. Data are shown as mean $\pm S D . * p<0.05$ compared to untreated cells.

association with hypoxia inducible factor 1 alpha (HIF1 $\alpha)$ required for the binding of NF-kB to the pyruvate kinase muscle isozyme M (PKM) promoter and PKM2, causing mitochondrial damage in glioblastoma cells (48). Similarly, in breast cancer fenofibrate induced apoptosis by activation of the NF-kB pathway since the effect was reversible by a NF-kBspecific inhibitor, and additionally, cell-cycle arrest at $\mathrm{G}_{0} / \mathrm{G}_{1}$ phase accompanied by down-regulation of cyclin D1 was observed. Subsequent in vivo experiments showed that tumor growth was attenuated in a xengograft breast cancer mouse model (49). Of major importance, especially in the context of hematological malignancies, fenofibrate was shown to significantly downregulate several pro-survival genes in mantle cell lymphoma including tumor necrosis factor-alpha (TNF-a) and NF-KB in a dose-dependent manner (50).

Our results demonstrated for the first time, that fenofibrate also reduces the proliferative capacity of MM and several lymphoma subtypes since it significantly reduced the viability of all tested myeloma and lymphoma cell lines by apoptosis induction due to reduced mitochondrial membrane potentials. Both human and murine cells were equally affected in a dose-dependent manner. Doses of approximately $50 \mu \mathrm{M}$ led to a significant decrease in cell viability in most myeloma and lymphoma 


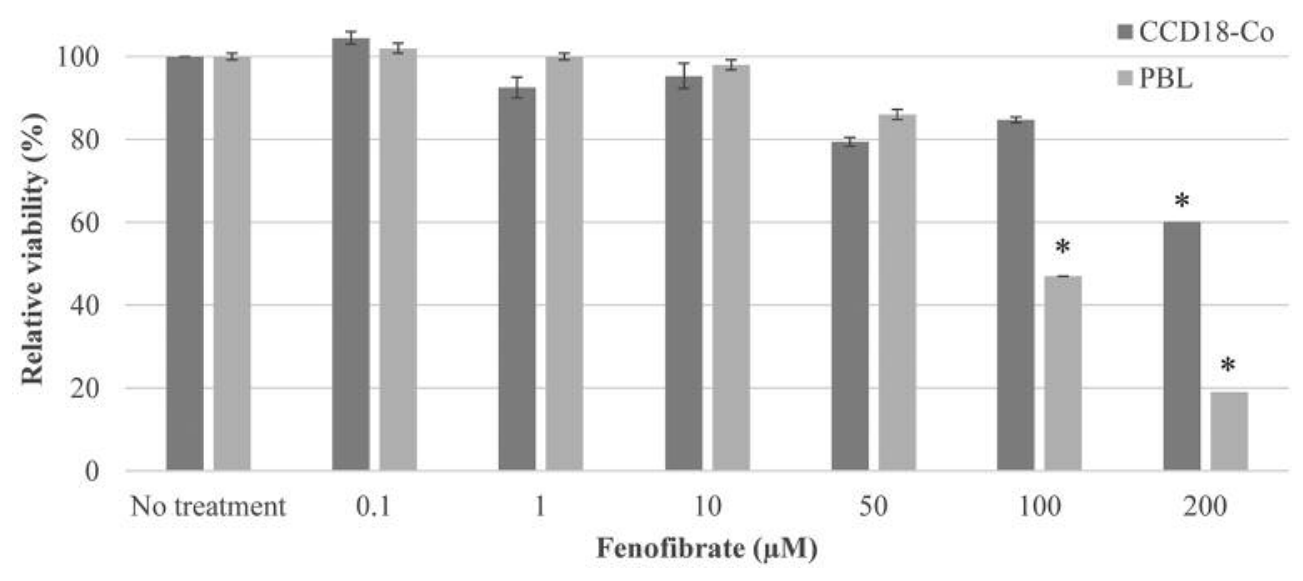

Figure 5. Effect of fenofibrate on viability of CCD-18Co cells and peripheral blood lymphocytes $(P B L)$ that served as healthy controls. Cells were cultured with fenofibrate for $72 \mathrm{~h}$. For CCD-18Co cells, viability was measured by the 3-(4,5-dimethylthiazol-2-yl)-2,5-diphenyltetrazolium-bromide (MTT) assay. For PBL viability and apoptosis was measured by 3'3-Dihexyloxacarbocyanine iodide (DiOC6) and propidium iodide (PI) staining in flow cytometry. Results represent data from three separate experiments. Data are shown as mean $\pm S D . * p<0.05$ compared to untreated cells.

cell lines. Interestingly, CCD-18Co colonic fibroblasts and PBLs, both serving as healthy controls, tolerated far higher fenofibrate concentrations, which, in turn, confirms the well-known safety profile of fenofibrate as a widelyprescribed drug.

Despite recent treatment innovations in myeloma treatment research, there still exists considerable scope in the identification of novel, and more importantly, more effective and sustainable therapeutic agents. Particularly, addressing specific genetic mutations as within the Wnt pathway in MM represent a promising treatment strategy and might improve treatment outcome and reduce therapyassociated adverse reactions due to a targeted inhibition of proliferation-enhancing effects. Due to its influence on Wntassociated signaling molecules in mantle cell lymphoma and several solid neoplasms, fenofibrate might also interfere with signaling molecules embedded in the Wnt and associated signaling pathways in lymphoma and MM. Fenofibrate demonstrated a significant cytotoxic potential towards both MM and lymphoma cells by apoptosis induction and slightly attenuated the propagation of healthy controls.

Since fenofibrate is efficacious at low effective doses in in vitro treatment of MM and as a widely-prescribed lipidlowering drug, it might represent a valuable agent for the utilization in MM treatment. Further in vitro studies using fenofibrate should be taken into consideration to delineate the exact mechanisms of action associated with the various patterns defining cellular survival in MM. Subsequent animal myeloma models are warranted to clarify its in vivo efficacy and toxicity in order to path a way for an initial clinical application in MM patients.
Hence, our results provide a rationale for advanced in vitro and in vivo studies using fenofibrate as a well-tolerated agent for the treatment of MM and lymphoma.

\section{References}

1 Palumbo A and Anderson K: Multiple myeloma. N Engl J Med 364: 1046-1060, 2011.

2 Howlader N, Noone AM, Krapcho M, Garshell J, Neyman N, Altekruse SF, Kosary CL, Yu M, Ruhl J, Tatalovich Z, Cho H, Mariotto A, Lewis DR, Chen HS, Feuer EJ and Cronin KA: SEER Cancer Statistics Review, 1975-2010, National Cancer Institute. Bethesda, MD, based on November 2012 SEER data submission, posted to the SEER website, April 2013.

3 Schmeel FC, Schmeel LC, Gast SM and Schmidt-Wolf IG: Adoptive immunotherapy strategies with cytokine-induced killer (CIK) cells in the treatment of hematological malignancies. Int J Mol Sci 15: 14632-14648, 2014.

4 Schmeel LC, Schmeel FC, Coch C and Schmidt-Wolf IG: Cytokine-induced killer (CIK) cells in cancer immunotherapy: report of the international registry on CIK cells (IRCC). J Cancer Res Clin Oncol 141: 839-849, 2015.

5 Rades D, Conde-Moreno AJ, Gebauer N, Bartscht T, Cacicedo J, Segedin B and Schild SE: Immunoglobulin G (IgG) subtype is associated with a favorable survival prognosis in patients irradiated for spinal cord compression from myeloma. Anticancer Res 36: 375-378, 2016.

6 Clevers H: Wnt/beta-catenin signaling in development and disease. Cell 127: 469-480, 2006.

7 van Andel H, Kocemba KA, de Haan-Kramer A, Mellink CH, Piwowar M, Broijl A, van Duin M, Sonneveld P, Maurice MM, Kersten MJ, Spaargaren M and Pals ST: Loss of CYLD expression unleashes Wnt signaling in multiple myeloma and is associated with aggressive disease. Oncogene 36: 2105-2115, 2017. 
$8 \mathrm{Su} \mathrm{N}$, Wang P and Li Y: Role of Wnt/ $\beta$-catenin pathway in inducing autophagy and apoptosis in multiple myeloma cells. Oncology Letters 12: 4623-4629, 2016.

9 van Andel H, Ren Z, Koopmans I, Joosten SP, Kocemba KA, de Lau W, Kersten MJ, de Bruin AM, Guikema JE, Clevers H, Spaargaren M and Pals ST: Aberrantly expressed LGR4 empowers Wnt signaling in multiple myeloma by hijacking osteoblastderived R-spondins. Proc Natl Acad Sci USA 114: 376-381, 2017.

10 Gooding S and Edwards CM: New approaches to targeting the bone marrow microenvironment in multiple myeloma. Curr Opin Pharmacol 28: 43-49, 2016.

11 Dutta-Simmons J, Zhang Y, Gorgun G, Gatt M, Mani M, Hideshima T, Takada K, Carlson NE, Carrasco DE, Tai YT, Raje $\mathrm{N}$, Letai AG, Anderson KC and Carrasco D: Aurora kinase A is a target of Wnt/beta-catenin involved in multiple myeloma disease progression. Blood 114: 2699-2708, 2009.

12 Butrym A, Rybka J, Łacina P, Gębura K, Frontkiewicz D, Bogunia-Kubik K and Mazur G: Polymorphisms within betacatenin encoding gene affect multiple myeloma development and treatment. Leuk Res 39: 1462-1466, 2015.

13 Sukhdeo K, Mani M, Zhang Y, Dutta J, Yasui H, Rooney MD, Carrasco DE, Zheng M, He H, Tai YT, Mitsiades C, Anderson $\mathrm{KC}$ and Carrasco DR: Targeting the beta-catenin/TCF transcriptional complex in the treatment of multiple myeloma. Proc Natl Acad Sci USA 104: 7516-7521, 2007.

14 Derksen PW, Tjin E, Meijer HP, Klok MD, MacGillavry HD, van Oers MH, Lokhorst HM, Bloem AC, Clevers H, Nusse R, van der Neut R, Spaargaren M and Pals ST: Illegitimate WNT signaling promotes proliferation of multiple myeloma cells. Proc Natl Acad Sci USA 101: 6122-6127, 2004.

15 Chapman MA, Lawrence MS, Keats JJ, Cibulskis K, Sougnez C, Schinzel AC, Harview CL, Brunet JP, Ahmann GJ, Adli M, Anderson KC, Ardlie KG, Auclair D, Baker A, Bergsagel PL, Bernstein BE, Drier Y, Fonseca R, Gabriel SB, Hofmeister CC, Jagannath S, Jakubowiak AJ, Krishnan A, Levy J, Liefeld T, Lonial S, Mahan S, Mfuko B, Monti S, Perkins LM, Onofrio R, Pugh TJ, Rajkumar SV, Ramos AH, Siegel DS, Sivachenko A, Stewart AK, Trudel S, Vij R, Voet D, Winckler W, Zimmerman T, Carpten J, Trent J, Hahn WC, Garraway LA, Meyerson M, Lander ES, Getz G and Golub TR: Initial genome sequencing and analysis of multiple myeloma. Nature 471: 467-472, 2011.

16 Kamihara Y, Takada K, Sato T, Kawano Y, Murase K, Arihara Y, Kikuchi S, Hayasaka N, Usami M, Iyama S, Miyanishi K, Sato $\mathrm{Y}$, Kobune $\mathrm{M}$ and Kato J: The iron chelator deferasirox induces apoptosis by targeting oncogenic Pyk $2 / \beta$-catenin signaling in human multiple myeloma. Oncotarget 7: 64330-64341, 2016.

17 Kim Y, Schmidt M, Endo T, Lu D, Carson D and Schmidt-Wolf IG: Targeting the Wnt/beta-catenin pathway with the antifungal agent ciclopirox olamine in a murine myeloma model. In Vivo 25: 887-893, 2011.

18 Schmeel LC, Schmeel FC, Kim Y, Endo T, Lu D and SchmidtWolf IG: Targeting the Wnt/beta-catenin pathway in multiple myeloma. Anticancer Res 33: 4719-4726, 2013.

19 Schmidt M, Sievers E, Endo T, Lu D, Carson D and SchmidtWolf IG: Targeting Wnt pathway in lymphoma and myeloma cells. Br J Haematol 144: 796-798, 2009.

20 Kim Y, Alpmann P, Blaum-Feder S, Krämer S, Endo T, Lu D, Carson D and Schmidt-Wolf IG: Increased in vivo efficacy of lenalidomide by addition of piroctone olamine. In Vivo 25: 99103,2011
21 Koller CM, Kim Y and Schmidt-Wolf IG: Targeting renal cancer with a combination of WNT inhibitors and a bi-functional peptide. Anticancer Res 33: 2435-40, 2013.

22 von Schulz-Hausmann SA, Schmeel LC, Schmeel FC and Schmidt-Wolf IG: Targeting the Wnt/beta-catenin pathway in renal cell carcinoma. Anticancer Res 34: 4101-4108, 2014.

23 Schmidt M, Kim Y, Gast SM, Endo T, Lu D, Carson D and Schmidt-Wolf IG: Increased in vivo efficacy of lenalidomide and thalidomide by addition of ethacrynic acid. In Vivo 25: 325-333, 2011.

24 Kim Y, Reifenberger G, Lu D, Endo T, Carson DA, Gast SM, Meschenmoser K, Nowak M and Schmidt-Wolf IG: Influencing the Wnt signaling pathway in multiple myeloma. Anticancer Res 31: 725-730, 2011

25 Lu D, Liu JX, Endo T, Zhou H, Yao S, Willert K, Schmidt-Wolf IG, Kipps TJ and Carson DA: Ethacrynic acid exhibits selective toxicity to chronic lymphocytic leukemia cells by inhibition of the Wnt/beta-catenin pathway. PLoS One 4: e8294, 2009.

26 Schmeel FC, Schmeel LC, Kim Y and Schmidt-Wolf IG: Piceatannol exhibits selective toxicity to multiple myeloma cells and influences the Wnt/beta-catenin pathway. Hematol Oncol 32: 197-204, 2014

27 Wall I and Schmidt-Wolf IG: Effect of Wnt inhibitors in pancreatic cancer. Anticancer Res 34: 5375-5380, 2014.

28 Schmeel LC, Schmeel FC, Kim Y, Blaum-Feder S, Endo T and Schmidt-Wolf IG: In vitro efficacy of cinnarizine against lymphoma and multiple myeloma. Anticancer Res 35: 835-841, 2015.

29 Schmeel LC, Schmeel FC, Kim Y, Blaum-Feder S, Endo T and Schmidt-Wolf IG: Flunarizine exhibits in vitro efficacy against lymphoma and multiple myeloma cells. Anticancer Res 35: 1369-1376, 2015.

30 Schmeel LC, Schmeel FC, Blaum-Feder S and Schmidt-Wolf IG: In vitro efficacy of naftifine against lymphoma and multiple myeloma. Anticancer Res 35: 5921-5926, 2015.

31 Schmeel LC, Schmeel FC and Schmidt-Wolf IG: Clofibrate demonstrates efficacy in in vitro treatment of lymphoma and multiple myeloma. Anticancer Res 36: 3395-4000, 2016.

32 Schmeel LC, Schmeel FC, Kim Y, Blaum-Feder S and SchmidtWolf IG: Griseofulvin efficiently induces apoptosis in in vitro treatment of lymphoma and multiple myeloma. Anticancer Res 37: 2289-2295, 2017.

33 Panigrahy D, Kaipainen A, Huang S, Butterfield CE, Barnés CM, Fannon M, Laforme AM, Chaponis DM, Folkman J and Kieran MW: PPAR alpha agonist fenofibrate suppresses tumor growth through direct and indirect angiogenesis inhibition. Proc Natl Acad Sci USA 105: 985-990, 2008.

34 Kuehl WM and Bergsagel PL: Multiple myeloma: evolving genetic events and host interactions. Nat Rev Cancer 2: 175-187, 2002.

35 Harousseau JL and Moreau P: Autologous hematopoietic stemcell transplantation for multiple myeloma. N Engl J Med 360: 2645-2654, 2009.

36 Moreau P, Hullin C, Garban F, Yakoub-Agha I, Benboubker L, Attal M, Marit G, Fuzibet JG, Doyen C, Voillat L, Berthou C, Ketterer N, Casassus P, Monconduit M, Michallet M, Najman A, Sotto JJ, Bataille R, Harousseau JL; Intergroupe Francophone du Myélome group: Tandem autologous stem cell transplantation in high-risk de novo multiple myeloma: final results of the prospective and randomized IFM 99-04 protocol. Blood 107: 397403, 2006 
37 Rosiñol L, Pérez-Simón JA, Sureda A, de la Rubia J, de Arriba F, Lahuerta JJ, González JD, Díaz-Mediavilla J, Hernández B, García-Frade J, Carrera D, León A, Hernández M, Abellán PF, Bergua JM, San Miguel J, Bladé J; Programa para el Estudio y la Terapéutica de las Hemopatías Malignas y Grupo Español de Mieloma (PETHEMA/GEM): A prospective PETHEMA study of tandem autologous transplantation versus autograft followed by reduced-intensity conditioning allogeneic transplantation in newly diagnosed multiple myeloma. Blood 112: 3591-3593, 2008.

38 Bringhen S, Avonto I, Magarotto V, Boccadoro M and Palumbo A: Investigational treatments for multiple myeloma. Expert Opin Investig Drugs 15: 1565-1582, 2006.

39 Hideshima T, Mitsiades C, Tonon G, Richardson PG and Anderson KC: Understanding multiple myeloma pathogenesis in the bone marrow to identify new therapeutic targets. Nat Rev Cancer 7: 585-598, 2007.

40 Fowler JA, Mundy GR, Lwin ST and Edwards CM: Bone marrow stromal cells create a permissive microenvironment for myeloma development: a new stromal role for Wnt inhibitor Dkk1. Cancer Res 72: 2183-2189, 2012.

41 Kocemba KA, Groen RW, van Andel H, Kersten MJ, Mahtouk $\mathrm{K}$, Spaargaren M and Pals ST: Transcriptional silencing of the Wnt-antagonist DKK1 by promoter methylation is associated with enhanced Wnt signaling in advanced multiple myeloma. PLoS One 7: e30359, 2012.

42 Kim Y, Gast SM, Endo T, Lu D, Carson D and Schmidt-Wolf IG: In vivo efficacy of the diuretic agent ethacrynic acid against multiple myeloma. Leuk Res 36: 598-600, 2012.

43 Messina CS, Weiher $\mathrm{H}$ and Schmidt-Wolf IG: Targeting prostate cancer with a combination of WNT inhibitors and a Bifunctional peptide. Anticancer Res 37: 555-559, 2017.

44 Yang LP and Keating GM: Fenofibric acid: in combination therapy in the treatment of mixed dyslipidemia. Am J Cardiovasc Drugs 9: 401-409, 2009.
45 Roberts WC: Safety of fenofibrate- US and worldwide experience. Cardiology 76: 169-179, 1989.

46 Yamasaki D, Kawabe N, Nakamura H, Tachibana K, Ishimoto K, Tanaka T, Aburatani H, Sakai J, Hamakubo T, Kodama T and Doi T: Fenofibrate suppresses growth of the human hepatocellular carcinoma cell via PPAR $\alpha$-independent mechanisms. Eur J Cell Biol 90: 657-664, 2011.

47 Wilk A, Urbanska K, Grabacka M, Mullinax J, Marcinkiewicz C, Impastato D, Estrada JJ and Reiss K: Fenofibrate-induced nuclear translocation of FoxO3A triggers Bim-mediated apoptosis in glioblastoma cells in vitro. Cell Cycle 11: 26602671, 2012.

48 Han D, Wei W, Chen X, Zhang Y, Wang Y, Zhang J, Wang X, Yu T, Hu Q, Liu N and You Y: NF-kB/RelA-PKM2 mediates inhibition of glycolysis by fenofibrate in glioblastoma cells. Oncotarget 6: 26119-26128, 2015.

49 Li T, Zhang Q, Zhang J, Yang G, Shao Z, Luo J, Fan M, Ni C, $\mathrm{Wu} \mathrm{Z}$ and $\mathrm{Hu} \mathrm{X}$ : Fenofibrate induces apoptosis of triple-negative breast cancer cells via activation of NF-kB pathway. BMC Cancer 14: 96, 2014.

50 Zak Z, Gelebart P and Lai R: Fenofibrate induces effective apoptosis in mantle cell lymphoma by inhibiting the TNFalpha/NF-kappaB signaling axis. Leukemia 24: 1476-1486, 2010. 